\title{
Psychology of Religion in China
}

\author{
Al Dueck • Buxin Han
}

Published online: 1 September 2012

(C) Springer Science+Business Media, LLC 2012

While the discipline of psychology in China is over a century old, psychological understandings of human cognition and personality are apparent in the writings of Confucius (551-479 BCE), Mencius (468-312 BCE), and Lao-Tze (4 ${ }^{\text {th }}$ BCE). For these great thinkers, the structure of the psyche was considered alongside moral and philosophical issues of good and evil, and the psychology of morality was seen as inextricably connected with the structure of the individual and the health of society. Although Confucianism is not generally considered a religion in China, the interrelation of psychology and morality is evident in one of Confucius' sayings:

Since I cannot get men pursuing the due medium, to whom I might communicate my instructions, I must find the ardent and the cautiously-decided. The ardent will advance and lay hold of truth; the cautiously decided will keep themselves from what is wrong. (Confucius 1997, Book X111, \#21)

As a science, Chinese psychology emerged concurrently with American psychology (Han and Zhang 2007). Yuanpei Cai studied with the German experimental psychologist, Wilhelm Wundt, and returned to China to become president of Peking University (1916) and the President of the Chinese Academy of Sciences (1927), where he established the Institute of Psychology. Daqi Chen established the first experimental laboratory in China at Peking University (1917). However, during the Cultural Revolution, the discipline of psychology was considered bourgeois and suffered a major setback. The teaching of and research in psychology was stopped entirely between 1966 and 1976. During these years political ideology and the psychological theories of the former Soviet Union dominated Chinese psychology. One fact stands out, among many others, with one exception, is that there were almost no Chinese scholars who studied psychology of religion even before the Liberation (1949).

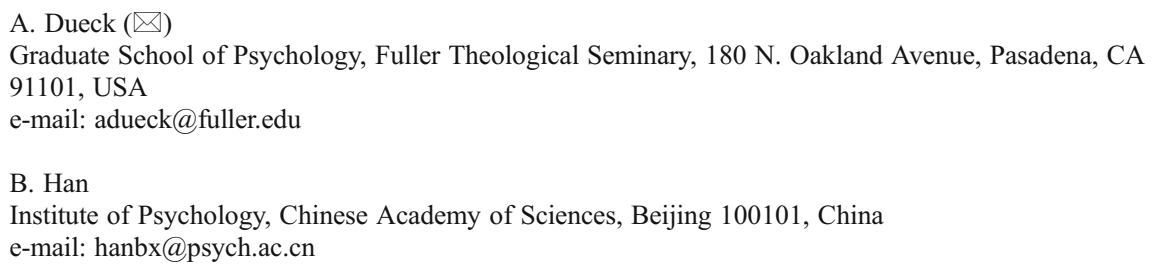


In the late 1970's and early 1980's psychology departments were reestablished in the major universities and the Chinese Psychological Society was reorganized. In 1980 there were only 5 departments of psychology in all of China, but over the past three decades this number has mushroomed to 200 , with some 2,000 masters level students and 100 doctoral candidates each year. In 2004, the Chinese Psychological Society proudly hosted the International Congress of Psychology. Another recent, and perhaps more significant development in Chinese psychology, is the increasing demand for indigenous approaches that address Chinese psychological concerns, as opposed to imported approaches from the West.

The dramatic increase in psychological institutions in Mainland China shows a major advance in 1998, when the central government announced a policy of educational reform. Psychology, as a discipline and profession, was regarded important to meet the nation's process of development. There were three stages of rapid improvements in psychology institutions (as indicated in Fig. 1 based on a preliminary investigation) 1956-1960 (after the Liberation), 1981-1985 (after the Cultural Revolution when psychology was considered a bourgeois discipline and profession (Han \& Zhang 2007), and 1994-2008 (when social and economic disparities increased and conflicts arose). From then on, psychologists were recruited to address social problems with psychotherapy. However, psychology of religion was not among those subfields. To date, there are 8 schools of psychology, 78 departments of psychology, in addition to 101 programs of psychology.

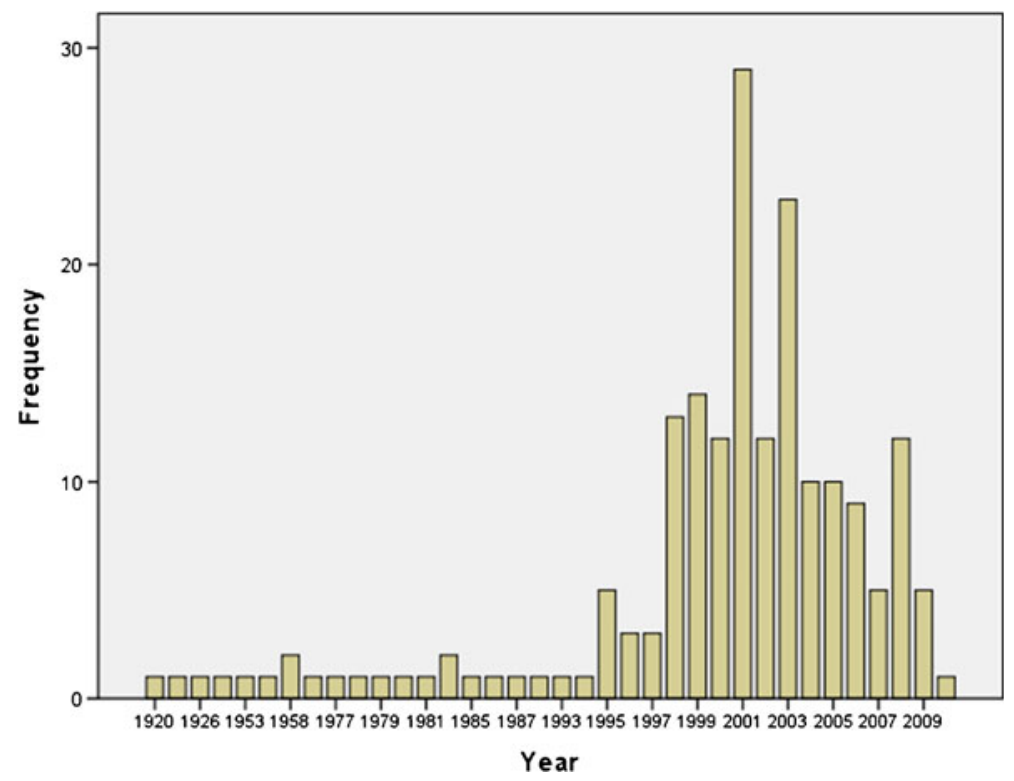

Fig. 1 Number of psychology institutions founded in Mainland China by year 


\section{Religion in China}

China's five officially recognized religions are Taoism, Buddhism, Catholicism, Protestantism and Islam. Recent research by Tong and Liu (reported by Wu 2007) indicate that there are some 300 million Chinese who identify themselves as religious/spiritual, the highest estimate to be published to date. Adherents to one of the five major religions account for $67.4 \%$ of this religious population. Two hundred million people are Buddhists, Taoists, or worshippers of legendary figures such as the Dragon King and God of Fortune, accounting for $66.1 \%$ of the religious persons. Twelve percent of all spiritual believers, or 40 million people, are Christians. In response to questions which addressed the role of religion, $24.1 \%$ of the religious group agreed that religion "shows the true path of life" and $28 \%$ agreed that it "helps cure illness, avoid disasters and ensure that life is smooth." The research also indicated that there has been an increase in younger believers since 2000 and $72 \%$ said they are happier as believers. Clearly religion is important to some $25 \%$ of Chinese society ( $\mathrm{Wu} 2007$ ); however, systematic study of religion from a psychological perspective is largely absent in Chinese universities.

The most remarkable event in recent Chinese history is the explosion of interest in religion. New public policy statements by the government have created more religious freedom. Fenggang Yang, a professor who heads the Center on Religion and Chinese Society at Purdue University in the United States, stated: "A growing interest in religion among the Chinese has boosted the country's fledging religion-related tourism market over the past decade" (cited in Shan 2010). The rising number of Chinese and Western tourists at religious places at the 130,000 religious sites on the Chinese mainland, is giving more people a chance to learn about religion.

Citing the results of a Chinese spiritual life survey conducted in 2007 by the Beijingbased Horizon Research Consultancy Group, Yang added: "Now, about 85 \% of the people in China hold some religious belief or practice some kind of religion." (Cited in Shan 2010). In China, folk religion is widespread among people who might not follow any institutional religion (Christianity, Islam, Buddhism) but practice fortune telling and feng shui. About $18 \%$ of the 7,021 respondents in the survey or approximately 200 million people claim to be Buddhist believers, which is an increase over the past decade from about 100 million, according to the estimation by the Buddhist Association of China.

\section{Psychology of religion}

In 1940, Chen Wenyuan wrote the first text integrating religion and psychology in China, entitled Religion and Personality. By the late 1980s Chinese scholars were writing texts describing Soviet and Western approaches to psychology and religion. Several Western textbooks on the psychology of religion were translated and published in China. Chinese psychologists began studying the psychological functions of worship, the personal usefulness of religion, the necessity of religion for survival, and the attitudes of youth toward religion. Chen (2003) wrote on Erickson's religious psychology and is currently writing a history of Western approaches of psychology to religion. A promising young scholar, Liang (2003), has conducted a comparative study of conversion among Buddhists and Christians in terms of gender, psychological factors, educational level, and cultural background. Nonetheless, Chen Yongsheng, a leading Chinese psychologist of religion, along with Liang Henghao and Lu Liqing, describe the current state of psychology of religion research as follows: "On building the discipline of psychology of religion, Chinese scholars have not discovered the 
central stream so far, and therefore it seems that the achievements are scattered and lack a solid foundation" (Chen et al. 2006, p. 156).

\section{Challenges}

Psychologists of religion in China face a wide range of challenges in the emergence of the discipline of psychology of religion. First, during the Cultural Revolution, psychology as a discipline was suspect. In the general population today psychology is increasingly accepted, but there is still reluctance to give it scientific status. Hence, Jing and Fu (2001) have strongly encouraged psychologists to make a contribution with their research to the larger society in order to obtain public approval. They state: "Psychology should devote itself to help Chinese people cope with the psycho-cultural shock that comes with social transition while at the same time preserving their psychocultural continuity" (2001, p. 416).

The lower scholarly status of psychology in the Chinese academic community is a problem. In the academy, psychology does not hold its own as a science in comparison with the physical sciences. Perhaps for fear of losing even more ground, some psychology departments are reluctant to broach the topic of religion. While psychology as a discipline has developed significantly over the past three decades, interest in psychology of religion is still emerging in psychology departments.

There has been little dialogue between Chinese psychologists of religion, other Chinese psychologists with similar interests, and Western psychologists of religion. We discovered that, until they attended the psychology of religion conferences begun in 2007, psychologists of religion had not met and, in some cases, did not know of each other's research interests. Also, Chinese psychologists have had minimal exposure to the body of research that comprises the field of psychology of religion in the West and only a few psychologists are aware of this literature. Classic texts on the psychology of religion written in the West are still largely unavailable in Chinese.

here is a paucity of research conducted on psychology of religion to date. Chen et al. (2006) reported that between 1994 and 2004, a search in the Chinese database of psychology articles revealed only 12 articles on psychology and religion. None were empirical studies. There was at that point an inadequate foundation for building the discipline using standard empirical and qualitative methodology. There remains some confusion regarding the appropriateness of qualitative methods of collecting data given the high value placed on empirical research. An ongoing challenge is how to develop the scope of the discipline when there continues to be ambiguity about the nature of religion and lack of direct knowledge about religions in China by psychologists.

This quote from Chen et al. (2006) captures the spirit of Chinese psychologists of religion:

First, psychology of religion exerts important influence on developing folk economy and social culture. The research achievements not only direct the religious travel and culture industry in the underdeveloped areas but also expand the folk religious travel related to foreigners and culture industry in developed areas. Second, psychology of religion has a unique role in maintaining the mental heath of the whole nation. A great deal of research has indicated that religious belief and customs are helpful for believers to keep their mental balance and well-being. In certain conditions religious persons can gain much better effects of psychology therapy—-for example, the thought of "something must be left to chance" in Taoism and yoga in Buddhism. Third, the importance of psychology of religion never can be underestimated in vindicating the human rights. 
China is multinational country with 56 nations, and every minority almost has its own particular customs and religion. We must fully respect the religion of each minority and make use of the knowledge of psychology of religion to promote the conversation and communication between various religions. This will help to strengthen the solidarity of the Chinese nation, to improve the level of human rights, and to safeguard world peace and development. (p. 159)

\section{Psychology of religion conferences}

Since September 2007, six psychology of religion conferences have been held. The first took place in 2007 at Zhejiang Normal University in Jinghua province. With the assistance of a graduate student then, Dr. Liqing Lu, Dr. Buxin Han was able to locate psychologists who were interested in religion and currently engaged in psychological research, either empirical or theoretical. In total there were 23 participants, including 8 graduate students. The research of the participants could be divided into two subgroups: theoretical (specifically history of Western psychology of religion, or comparison of Chinese and Western psychology of religion) and empirical. Research covered Protestantism, Catholicism, Buddhism, Taoism, Confucianism, and Islam.

The second conference held in Beijing in March 2008, was attended by 45 individuals with 29 presentations. The attendees again included both faculty and graduate students. A sample list of some of the presentations included: "On Jungian psychology of religion;" "Cognition and brain research on the placebo effect and its implications for the psychology of religion;" "Relationship of college students' spirituality, community, and happiness;" "The development of a Chinese spirituality scale;" and "The psychology of filial piety in Christianity and the Tao."

The third conference, held in March 2009 with attendance this time reaching 120, was sponsored by Sichuan University in conjunction with the West China Hospital. The focus was on psychology of religion in service of a society traumatized by disaster, specifically the 5/12 earthquake. The chief psychiatrist of the hospital, Professor Yanchun Yang, had extended an invitation and her opening comments to the conferees began with a message that encouraged psychologists of religion to be more sensitive to the Chinese context as they researched earthquake survivors and to include spirituality as part of the assessment and treatment of trauma.

Over the first three conferences we noticed significant changes. Not only were there more participants, there were also more presentations, and discussions of the papers had greater depth. Particularly satisfying was the fact that the Chinese hosts of the conference took full responsibility for the conference. All of the speakers gave their presentations in Chinese and translation was made available for Westerners. As a result of these conferences we now have a collection of excellent presentations that merit publication. Lack of time and financial support made pursuing publication impossible at that point. The papers in this issue had their impetus in those early conferences.

With the support of The John Templeton Foundation and the Fuller Foundation, the Fourth Annual International Conference of Psychology of Religion (2010) was held at Qufu Normal University located in the city of Confucius' birth and a culture highly supportive of research in psychology of religion. In the three-day conference, 45 Chinese psychologists and students in psychology, together with eight Western psychologists, gave papers on topics including: attachment theory and modes of spirituality, neurophysiology and religious experience, indigenous forms of spiritual therapy, religious coping research, and spiritual themes among Sichuan earthquake survivors. The audience was more than 200 persons for each presentation.

A conference highlight was the debate among the Chinese psychologists and the larger audience about the nature of religion generally, and in China in particular. How does one 
develop a discipline of psychology of religion in a society that historically did not have a word for religion? Does one talk about God in the same way in a culture shaped by Confucius and Lao-Tze? How does spiritual formation occur in Chinese society? What will be uniquely Chinese about the research on psychology of religion in China? Is there a "god center" in the brain? Can religion contribute to harmony in society or in therapy?

In January 2011 Fuller Graduate School of Psychology sponsored a one-day student conference on psychology of religion at China's prestigious Institute of Psychology. We found students eager for additional exposure. Forty local students attended and 17 presentations were given. It was delightful to see how in the research students instead of using "off the shelf" instruments, were carefully constructing their own culturally sensitive instruments after using focus groups.

The fifth psychology of religion conference was held at Minzu University in March 2011, an institution known for its commitment to the positive role of religion in society and the life of ethnic communities. Minzu is one of China's many educational institution dedicated to educating minority students. The enrollment at Minzu is composed of $90 \%$ ethnic students from China's 56 ethnicities. The conference had the largest number of presentations to date with a significant number of new scholars joining the group. There were 45 presentations and an audience of 200 persons.

The sixth psychology of religion conference was held at East China Normal University in Shanghai in March 2012. While the attendance was somewhat lower, more than 50 papers were given, the largest number to date. It was a unique experience to have more scholars of religion present at the conference. There was concern raised that too much psychology of religion is focused on Christianity, a problem echoed by Western psychologists as well (Belzen 2009). There were Chinese presenters who argued passionately for the treatment of spirituality with seriousness in mental health services. More than in previous conferences cross-cultural and ethnic perspectives were evident.

\section{Recent publications and activity}

These conferences and the scholarly relationships that emerged have borne fruit in a variety of ways. The Chinese Academy of Social Sciences published two papers by Western participants in their journal, The Religious Cultures in the World, the Annual of Religious Studies in China. The Chinese scholars attending the conferences committed themselves to translating a number of Western texts in psychology of religion including: Nelson (2009). Psychology, religion, and spirituality; Pargament (1997). The psychology of religion and coping: Theory, research, practice; Jeeves and Brown (2009). Neuroscience, psychology, and religion: Illusions, delusions, and realities about human nature; Hood et al. (2009). The psychology of religion: An empirical approach; Wulff (1991). Psychology of religion: Classic and contemporary views; and Paloutzian and Park (2005). Handbook of the psychology of religion and spirituality. The first four are translated and in the process of being published.

A major project undertaken by scholars in the group was to write an edited collection of essays on the state of the art and future projections for psychology of religion in select areas to be used in graduate education in psychology of religion. The essays by the Chinese scholars in this special volume are translations of the essays to be published in China (Han and Dueck in press). The goals for the book of essays were to: a) provide an overview of the history of psychology of religion in the West and in China with reference to the needs of Chinese society; b) explore future directions for the field; c) provide a collateral text for university-level instruction on the psychology of religion; and d) encourage rigorous, scholarly research in the psychology of religion. 
At the request of Chinese universities, thousands of books in Western psychology and psychology of religion have been donated to university libraries. Books have been shipped to fourteen universities including Beijing Normal University, Fudan University, Fujian University, the Institute of Psychology, Nanjing University, Qufu University, Shaanxi University, and Zhejiang Normal University. The upshot of these efforts is the establishment of a solid foundation for an informal network of psychologists of religion and a growing interest in psychology of religion research.

Some universities have been offering a course in psychology of religion such as Zhejiang Normal University, Fudan University, Beijing Normal University, and Minzu University. Other universities are offering a psychology of religion course for the first time. New scholars are considering $\mathrm{PhD}$ programs in psychology of religion. Various American universities have been contacted about hosting Chinese students and scholars to study psychology of religion at their institution.

The essays in this volume are the result of a two-year grant from the John Templeton Foundation and the Fuller Foundation. The authors were the principal investigators. The goals of the project were to support the efforts of Chinese psychologists interested in religion to advance their knowledge in the field of psychology of religion; to develop an intellectual exchange between Chinese and American psychologists with a focus on current research and scholarship in the field of psychology of religion; and to develop an association for psychologists of religion in China.

\section{Reflections on Chinese psychology of religion-recent progress}

The essays by Eastern and Western psychologists of religion in this double issue of Pastoral Psychology are divided into seven sections: historical perspectives, methodological considerations, western psychological approaches in Chinese perspective, religious traditions, conversion, religion and healing, and spirituality and human development. However, in this section, we will focus on the unique contribution of the Chinese psychologists as they navigate new terrain in developing an indigenous psychology of religion. We will reflect first on the chapters by the Chinese psychologists of religion and then the American authors in terms of the respective themes that emerge. For the former there is a concern to recover religion in ancient traditions, to affirm cultural indigeneity, to explore new methodologies, and to examine the changing nature of religious beliefs.

\section{Recovery of the ancients and their religion}

While Jung never visited China to learn the wisdom of the ancient sages, one Chinese scholar, Liqing Lu, has reflected deeply on religious meanings and spirituality in human nature in the ancients. The discipline of psychology in the modern Chinese and Western world emerged in the latter part of the $19^{\text {th }}$ century but that does not mean that there were not psychologically astute thinkers prior to that time. Lu and Ke point out in their essay, "A Concise History of Chinese Psychology of Religion" that during the Spring and Autumn and Warring States periods (770 BCE to $221 \mathrm{BCE}$ ), debates about "human nature" were central to the development of a future psychology of religion. They examine how Confucius' ethical teachings are connected to psychological assumptions about human teachability and the possibility of change by effort. Their analysis of Mencius, Xunzi, Mozi, and Taoism all point to the inextricable relationship between religion, spirits, and ethics with human nature, whether good, evil, innocent, or neutral. They state there were three principle attitudes 
towards religion: support, rejection, and reform. With regard to folk religions of the lower social classes, their implicit psychology of religion was utilitarian in nature; religion was sought for worldly benefits and spiritual solace.

It is generally assumed in China and in the west (Fingarette 1972) that Confucianism and Traditional Chinese Medicine are secular, not religious. Two essays propose the opposite, namely, that traditions in ancient and modern China have a religious flavor and are deeply connected to healing. That is the focus of Qimin He in her essay entitled "Religious Traditions in Local Communities of China." She believes that the traditional religions based on the patriarchal clan system are the bedrock of Chinese spirituality. This system has fundamentally shaped the religious psychology of Chinese people and borrowed religions. Following the lead of the well-known Chinese scholar, Mou (Mou and Zhang 2000), she believes that original and foreign religions can exist peacefully side-by-side. She describes both the variety of religions and the diversity of ethnic groups and shows how they interact. Islam has adapted to Chinese culture as can be seen in the architecture of their mosques. They adhere to the teachings of Islam and they follow traditional Chinese ethical standards such as loyalty, filial piety, benevolence, and righteousness. She points out that Christianity, in comparison with Buddhism and Islam, has remained more distant from traditional ideologies and subcultures in China. Like some of the other authors, Qimin He is working from within a cultural psychology of religion paradigm. It is her hope that psychotherapists would respect the patient's cultural and religious background when they make an intervention.

Shi and Zhang focus on themes of spirituality in Traditional Chinese Medicine (TCM), which is still popular today after being practiced for thousands of years. The authors argue that its longevity is a consequence of its spiritual roots. It focuses not only on the illness of a person but the person as a whole; it cares for the body and nourishes the spirit. They maintain that notions of Yin-Yang and Qi have spiritual origins in that they are related to heaven, earth, and life. The authors find spiritual dimensions in the healing rituals. In the book Shang Shu we are told: "Zhu, is the one who contacts gods" and "Mr. Zhou prayed for King Wu's illness, and then he recovered." In terms of Chinese pharmacy, what seem like unscientific medicines to us were advocated because "everything has spirits." TCM borrowed from Taoism, Confucianism, and Buddhism the importance of cultivating the mind, nourishing the heart, and developing wise character. Master doctors of TCM were similar to religious leaders in their effort to help people rise above bitterness, illness, and loss. Hence the authors conclude that TCM is not simply a collection of techniques but is deeply concerned about the person as a whole, including spiritual suffering.

Biao Chen makes the case in his essay, "Coping With Death and Loss: Confucian Perspectives and the Use of Rituals," that Confucian teachings about death are integral to contemporary Chinese responses to death. Confucius is well known for his saying that if you wish to understand death, you must first understand how to live. To die a worthy death is to have lived a moral life. However, death is nonetheless given meaning by being contained within ritual. Chen asserts that it is integral to Chinese culture in that it creates ethical order and gives spiritual significance to death. It does so by creating elaborate death rituals around notifying family and friends, preparing the corpse, assuming mourning status, offerings, hiring ritual specialists, placing the body in the coffin, processing after the coffin, the burial, the funeral feast, eliminating pollution and various post burial tasks. Chen emphasized that the death rituals have psychological significance in that they bond families together, experience emotional release, reinforce the importance of filial piety and collectivism, and assumes an ethical order. Chen skirts the issue whether Confucianism is a religion but he is confident that participants in these rituals gain spiritual growth. He points out that spirituality 
in China may be different from the West in that in China, the spiritual is part of the personality of all people including non-traditional religious and common people that are open to the transcendent.

To summarize, the Chinese psychologists of religion are rewriting the understanding of the ancient traditions as spiritual rather than secular in nature. Religion, folk culture, medicine, ethics, and religious anthropology seem to interpenetrate each other.

\section{Indigeneity}

In an essay entitled "Use of Religious Resources in Psychotherapy from a TraditionSensitive Approach: Cases from Chinese in Malaysia," Ting and Ng focus on the integration of spiritual and religious themes in the three major religions of Taoism, Buddhism, and Christianity with psychotherapy. The unique practices of these religions include the blending of religion, folklore, traditional practices, and loyalty to the religious tradition of one's family. The authors compare the religions in terms of the common beliefs in spiritual reality, their explanations of suffering, ways to relieve suffering, and the ways healing takes place. Cultural differences between Southeast Asians and the West suggest that the clients in the former are more family-oriented, prefer spiritual explanations of mental problems and integrate the official religion with folk practices in the community. It is a fundamental belief that disturbance in the spiritual realm results in mental illness and demon possession. Hence, Ting and $\mathrm{Ng}$ call for a therapeutic approach that honors the religious tradition of clients. Using a tradition-sensitive approach, they present cases in which the client's religious beliefs are explored, religious duties are affirmed, their basic religious teachings and rituals are built on, and religious support from the family and community are accessed.

A concern for the importance of indigeneity is clearly articulated by Wang Xuefu when he states in his chapter, "On Becoming a Religious Therapist in Chinese Culture," that contemporary Chinese psychology is but Western psychology transplanted to China and that Chinese healers have turned a deaf ear to their own rich heritage of psychological thought. He quotes a Chinese proverb, "Unaware of the inexhaustible wealth of his family heritage, he begs from door to door to stay alive." The indigenous model of psychotherapy developed by Wang Xuefu is one he calls Zhi-Mian (facing life directly). His first graduate degree was in Chinese literature with a focus on Lu Xun, China's first modern short story writer. He is concerned to develop a psychological approach that is sensitive to the Chinese context and so Wang cites proverbs and tells stories in therapy. He hails Confucianism as a teaching therapy and Taosim as capable of addressing compulsiveness. From “Ah Q," a character in Lu Xun's short stories, he finds a diagnosis of passivity and escapism in Chinese society, a consequence of national and international oppression. The opposite is the spirit of a real warrior willing to face life directly rather than creating excuses for one's escapism. Wang finds here the cultural roots of many psychological symptoms. This, he suggests, will require discernment of what is nourishing and encouraging emotional connectedness to others and to God. The other major source for Wang's approach is the theological writing of Bishop K. H. Ting, the former leader of the Three-Self Protestant church in China. From his work he draws the themes of recognizing one's finiteness, the importance of God's cosmic love, a theology of suffering and inclusiveness, the struggle to face harsh realities, the rejection of coercion and following the example set by Jesus. Following the lead of Bishop Ting, Zhi-mian psychotherapy is open, receptive, non-judgemental, spiritually sensitive, and inclusive.

It is a good sign when local writers feel some pride when their cultural resources have shaped other cultures. Chinese psychologists are no exception. Of course, it 
requires a measure of humility on the part of receiving cultures in that, what they have claimed as truth, was known in another culture long before their own. Chinese culture has given the West more than the famous four: paper, gunpowder, the compass, and printing. Henghao Liang in his essay "Jung and Chinese Religions: Buddhism and Taoism" refers to Jung as an Eastern philosopher living in the West. He examines the relationship between Jung's psychological theories and Chinese religions and finds significant similarities between Jung's concepts of synchronicity, Self, and his principles of the psyche, the mandala, with concepts in Chinese Taoism. Through Richard Wilhelm Jung absorbed the wisdom of the East, the meaning of the I Ching, the theory of Taoist inner alchemy, and improved his technique of active imagination. Jung's notion of unity of opposites has its roots in both Taoism and Buddhism. Liang suggests that perhaps Jung's idea of the "collective unconsciousness" is equivalent to the eighth consciousness in Buddhism, Alaya Consciousness.

The concern for indigeneity is also raised by Ren Zhengjia who asks whether indigenous spirituality and community play a significant role in times of crisis. He reflects on his own involvement in providing care after the Sichuan earthquake which took place 5/12/2008 with more than a 100,000 deaths. He believes crisis workers need to appreciate deeply the personal, cultural, and spiritual resources that victims bring to the crisis event. He believes that Chinese spirituality can be involved in the process of psychological rehabilitation. Ren too wrestles with the definition of spirituality in China. After reviewing some of the fundamental tenets of Confucianism, Taoism, Buddhism, and folk religions, Ren shares poignant stories in which a survivor's spirituality enabled them to cope. His crisis intervention team honored and encouraged indigenous forms of spirituality.

In her article, "The Worldview of Healing Tradition in the East and West: Its Implication for Psychology of Religion," Sing-Kiat Ting compares two regions of the world in terms of mind-body dualism, views of the self, the nature of mental health, the value of relationships, the role of community, and the relationship between healing and spirituality. Appropriately, she begins with reflections on the nature of culture. Culture for her is not static but fluid, improvisational, transformational, and political.

Fundamentally, Western culture privileges the individual while Eastern cultures privilege relationships and the common good. It is her hope that a cultural psychology of religion would be sensitive to differing worldviews and that each culture would avoid imposing its definition of mental health or healing on the other. She maintains that if spirituality or religion is to nurture the well-being of local people, then local persons would need to be shapers of their own religious tradition and express their faith in their local dialects. She finds herself attracted to indigenous forms of psychology as they have emerged in the Philippines and New Zealand. She is concerned about uncritical importation of foreign approaches to mental health into China.

In summary, the desire for indigeneity emerges in the chapters by the Chinese psychologists of religion. This is also apparent in Chen and Chen's article (The Methodological Issues in Psychology of Religion Research in the Chinese Context) which is concerned that psychology of religion must assist with national goals and reflect Chinese worldview. In contrast to the American scene, Chen et al. point out astutely that Wundt's cultural analyses of religion seems to have received much greater attention in China than in the West. Consistent with a cultural point of view they are concerned that in the future greater emphasis be placed on practical application of psychology of religion for the sake of a harmonious society. Chen believes that the goal of a harmonious society must shape the development of a psychology of religion. 
New methodologies and surprising findings

Noteworthy is a theme in the chapters written by the Chinese scholars calling for methodological innovation. China's foremost methodologist and empirical researcher is Yongsheng Chen of Zhejiang Normal University. Chen and his colleagues (Wang, Weng and Wang) point out (History, Present Situation and Problems of Chinese Psychology of Religion) that research in psychology of religion had already begun at the turn of the last century but flourished in the post cultural revolution era. The progress thereafter has been remarkable with major efforts in translation of classic Western texts in psychology of religion; theoretical analyses of James, Erikson, Wundt, and Allport; the development of new measurement tools; and empirical social analyses of religion and mental health, religious cognition, and religious emotions.

Chen and Chen (The Methodological Issues in Psychology of Religion Research in the Chinese Context) write an appreciative review of research conducted by Wulff, Barrett, Slife and Nelson before proposing their own approach. They argue for a problem oriented approach and the diversification of methods to include qualitative, quantitative, historical and theoretical models. They are convinced that no single research method can reveal the uniqueness and complexity of religious phenomena. They point to the unique social and cultural background for the study of psychology of religion in China. The current goal of building a harmonious society should exert influence on the development of a psychology of religion. They believe that a commitment to dialectical and historical materialism will shape the research process. Lest there be readers who think that a psychology of religion is impossible with an explicitly atheist government, they remind us that Chinese citizens have a constitutional right to religious freedom. They encourage an increase in research on the local origin of Chinese folk beliefs that is characterized by the integration of Confucianism, Buddhism, and Taoism.

A canon of scientific method is the importance of replication. In the process of replicating the religion and health findings in the west, there is research in Chinese psychology of religion which breaks new ground in China and perhaps has implications for the Western research on religion and trauma. Most Western researchers have found a positive relationship between religion and mental health. Wang, Wang and Han ("The Mental Health of Older Buddhists after the Wenchuan Earthquake") examine the mental health of older Buddhists and a matched sample of nonreligious individuals after the Wenchuan earthquake. Using a mental health inventory for the elderly, they found that the older Buddhists in the more severely damaged area of Beichuan, 4 months after the disaster, scored significantly lower than nonreligious participants. After 10 months their scores were significantly better. The authors conclude that religious faith helped Buddhists recover from trauma. However, the lower level of mental health scores initially was interpreted to mean that those with religious sensitivities were more deeply affected by the trauma of the earthquake. The authors comment that since Buddhists accept stress as a part of their daily lives and also emphasize the fundamental goodness of the world they experienced a greater discrepancy between the reality of the earthquake and this positive conception of the world. Hence the greater the negative effect on Buddhist behavior and mental health.

To recapitulate, there is a theme in the Chinese writers that emphasizes the importance of new methods, local studies of validity, and a diversity of methods. In sum, their methodological sophistication is growing and their research findings are novel and worthy of the attention of Western psychologists of religion. 
The changing nature of belief in contemporary China

A number of chapters focus specifically on religious belief and radical religious change in China. Song and $\mathrm{Fu}$ report on the religious beliefs of college students ("The Study of College Students' Beliefs in China") which is closely followed by the Chinese government. In the last decade, considerable research has been conducted on college students' beliefs from the perspective of psychology which included the spirituality of college students, the relationship between belief and mental health, and cross-cultural research on the beliefs of college students in two ethnic groups. The results of Song's research revealed that social beliefs (such as loyalty to the nation and political beliefs) took priority over pragmatic beliefs (loyalty to family, desiring money) with religious belief in last place (worship, supernatural being, personal soul). Women score higher on religion than men and overall, the authors estimate that $13 \%$ of college students hold religious beliefs. However, the number of college students who hold religious belief is increasing from their first to their senior year. As in the West, students tend to form religious belief when encountering crises, when unable to trust the surrounding world, or when seeking restored physical and mental health. Beliefs in the supernatural had a positive effect on interpersonal sensitivity and reduced depression and anxiety among Han. Song and his colleagues did find both common and distinguishing characteristics between the Han majority and ethnic Zang college students with the latter putting religious beliefs in second rather than in last place.

While the topic of conversion is ubiquitous in Western psychology of religion, in China the work of Liping Liang is well known. Based on her qualitative and quantitative analysis she sought to uncover the meaning of religious experience and to explain how sacredness and earthliness, utility and truth resonate in the spiritual world of Christian and Buddhist believers. She found that the initial motivations for making contact with religion were seeking spiritual relief, physical health, and truth or wisdom. The more educated converts (whether Buddhist or Christian) sought for truth while lower educated persons wanted physical health. More persons who converted to Christianity (66\%) than to Buddhism (46\%) did so because of the persuasiveness of the doctrine. For others, it was belonging to a religious community or because of the perceived benefits from a spiritual life and practice. The main factor that enabled converts to maintain their religious beliefs and practices were the changes they experienced as they continued their journey of transformation.

These two papers point to the fact that Chinese psychologists are clearly interested in the religious beliefs of individuals and groups. Their results show diversity of religious beliefs across ethnic groups, religious groups, gender, and some similarities with Western findings.

\section{Western perspectives on Chinese psychology of religion}

Four Western scholars and their research colleagues reflected on Chinese psychology of religion from a range of perspectives. In each case they addressed a major topic of research in psychology of religion in the West and then pondered its usefulness in the Chinese context. As Jacob Belzen (2009) has stated repeatedly over the past decade, psychology of religion needs to be viewed from within a cultural context. The essays written by the psychologists from the US attempt to do so. Several themes emerge from their chapters: the importance of writing a local history of psychology of religion, community in collective culture, the indigeneity of American psychology of religion, models of religious transformation, and the importance of interdisciplinarity and diversity of methods. 
On writing history

James Nelson in his essay entitled "History of the Psychology of Religion, East and West: Theoretical and Practical Principles for New (and Old) Histories" is concerned about how we write history, specifically the history of psychology of religion as it is being written in a Chinese context. Critical, he suggests, is our view of history, whether it is seen as linear progress, tragedy, or a complex narrative. Each view of history assumes a definition of purpose, time, and the nature of change. Each approach has advantages and disadvantages. He encourages Chinese psychologists to write a history of psychology of religion in China from a Chinese perspective while at the same time engaging in a conversation with the West. He wonders whether in the Chinese context the narrative approach would be most appropriate in developing multiple, limited, and focused histories.

In his chapter entitled "A History of Psychology Religion in the West: Implications for Theory and Method," James Nelson suggests that in the past, three paradigms shaped the study of religion: hermeneutic-phenomenological, positivistic naturalism, and religious integrative psychology of religion. Each paradigm has its basic characteristics and assumptions regarding ontology, ethics, epistemology, and methodology. In the past 100 years in the Western study of psychology religion, the positivistic naturalistic paradigm has been preferred but it is the least helpful in generating new ideas in psychology of religion and addressing issues of ethics and values. He wonders whether the implicit universalism conflicts with the Chinese psychologist concerns about indigeneity. Nelson provides examples of individual Western researchers for each paradigm. Forgiveness research and mindfulness-based cognitive therapy are examples of approaches that are sensitive to religious theory and practices. In the end he recommends moving beyond a method centered approach to a focus on the object of study for psychologists or religion, namely, religious traditions and people who inhabit them. Consequently he encourages greater use of qualitative approaches.

\section{Community in a collective culture}

In their essay, "Community, Spiritual Traditions, and Disasters in Chinese Society," Al Dueck and Katie Byron explore the role of a deeply contextual and communal therapy in the context of a collective culture in response to natural and human disasters. Various Chinese leaders have called for those working with the traumatized to consider the localities and heritage of China in the construction of psychotherapy for Chinese rather than the wholesale importation of Western models. This is best illustrated by the work of Yang Yanchun (Yin and Yang 2010) whose team responded to the 2008 earthquake in Sichuan by taking spirituality and community seriously. Dueck and Byron suggested that trauma impacts a social system but may leave some system resources intact. They think that perhaps Walsh's (2007) four ways of reconstructing communities could be a resource for detoxifying the effects of trauma and disaster: shared acknowledgement of the traumatic events, shared experience of loss and survivorship, reorganization of the community, and reinvestment in relationships. Dueck and Byron follow the work of Landau and Weaver (2006) which suggests that spirituality can also play a positive role in the recovery of meaning and community after disaster when honored rather than instrumentalized. In the long run, healing from disaster requires the rebuilding of communities and religious communities who can be allies rather than adversaries in this process. Such rebuilding requires a psychology that is more community oriented and morally sensitive in a society that is becoming increasingly religious. 
Most appropriate for a more collectivist culture, James Nelson explores theory and method for a community-oriented psychology of religion in his essay "Taking Community Seriously: A Theory and Method for a Community-Oriented Psychology of Religion." He points out that psychology of religion in the West has been strikingly individualistic in its approach. However, religion is a set of beliefs and practices of a group often supported by institutions. Moreover, cross-cultural psychology of religion does not much allow for surprises. Nelson cites a study in which the investigators assumed religion was universally the same and when the data did not support their assumption they used post-hoc analyses to demonstrate differences. Nelson proposes that if the philosophy of science implicit in Western psychology religion were altered to take a more relational approach, our scientific study of religion in psychology would also change. After all it is a scientific canon that the method of the scientist should be compatible with the object of study. Nelson is critical of psychologists who use individual questionnaires to study religious practices and fail to examine how the practices function in a group. He hopes that a community-oriented psychology of religion will embraces a greater diversity of methods, both qualitative and quantitative, that capture both human uniqueness and relationality. This approach might involve groups to be studied participate in the design of the study. Nelson also proposes that we be more concerned about direct benefits to the people we study, i.e., how are the goals of the religious community advanced. That would mean that researchers would need to know what the needs of the religious group are. He concludes that a movement away from a metaphysics of invariant, universal natural laws suggests that psychology of religion research should focus on specific benefits to individuals in their communities.

\section{Indigeneity of American psychology of religion}

The American authors were consistently sensitive to their own cultural context with a commitment to honoring the Chinese context. Brent Slife outlines in his essay, "Religious Implications of Western Personality Theory" some of the religious implications of Western, personality theories such as psychoanalysis, behaviorism, and humanism. All of these theories are presumed to be vigorously secular and naturalistic, that is, they are almost anti-religious and seek to explain behavior in terms of natural laws or mechanisms. Freud thought of religion as a projection; Skinner's theory seems to have no room for genuine altruism. Carl Rogers' emphasis on individual freedom and actualization is in conflict with more communal understandings of religion. Slife also examines the more non-dualist postmodern theories of social constructivism and hermeneutics. These are much more relational theories of personality that place emphasis on meaning, including religious meanings. However, Slife points out that many religious persons would not acknowledge that their religious beliefs were simply constructed meanings. There would be no reason to deeply commit oneself to them.

In a related article "Conceptualizing Religious Practices in Psychological Research: Problems and Prospects," Slife and Reber show how the Western concern for methodological rigor can compromise the rich meanings of religious practices. Western research tends to simplify and reduce the focus of study rather than to preserve meanings. As a result there is the potential mismatch between what is intended to be studied and what is actually studied. They begin by reviewing two Western research traditions: instrumentalism and operationalism. Instrumentalism assumes that the critical question is how efficient means are in terms of achieving a particular end, e.g. what therapy most quickly reduces symptoms. The danger is that religion may simply become a means to some end. Slife and Reber cite as example a study that asked whether prayer for one's partner could reduce infidelity, i.e., how effective 
is prayer. However, prayer for most religious persons focuses on God not the efficacy of one's prayers. Should the worship of a deity be understood from an instrumental perspective? Operationalism is the process of the defining variables so they are observable and amenable to empirical study. However spirituality is not scientifically observable. Nonetheless it is operationalized in terms of church attendance or responses to questionnaires. To love may involve hugs, but to hug is not synonymous with loving. Thus what we intended to study may not be what we actually research. The researchers in the study cited had operationalized prayer in terms of the frequency and content of the prayer via responses to a questionnaire. After running the study the researchers concluded that prayer for one's partner significantly predicted lowered infidelity and gave tips on how to pray more effectively. Slife and Reber argue that what the researcher hoped to study (effect of prayer on the partner's fidelity) was not what was actually studied, namely, prayer and fidelity, but what they examined where numerical responses which presumably were related to prayer and fidelity. However that was an assumption.

In his chapter, "Religious Experience, Development, and Diversity," Hoffman begins by pointing out that too often childhood spiritual experiences are viewed from the perspective of adult spirituality rather than viewing the child's experience as unique and important in and of itself. He points out that many developmental theorists assume that early childhood experiences such as attachment to caregivers will shape the nature of adult religious experiences such as conversion. Those children who came from a home where parents avoided emotional attachment, later as adults were more likely to have an intense conversion experience. And since research suggests that culture affects attachment styles, one would also expect differences in images a person has of God. Hoffman concludes that the Western assumption of a universal theory of human development in relation to spirituality has crippled our understanding of cultural impact.

\section{Models of transformation}

Lewis Rambo and Steven Bauman in their essay "Psychology of Conversion and Spiritual Transformation" assume that conversion is a process of religious change that occurs in a dynamic context of people, institutions, events, ideas and experiences. However, the personal dimension is not sufficient to explain conversion; it also demands that we take into account social, cultural, and religious dynamics. They propose a model in which religious conversion takes place in stages: context, crisis, quest, encounter, interaction, commitment, and consequences based on Rambo's classic text, Understanding Religious Conversion. Rambo and Bauman point out that the cultural factors are often ignored or downplayed in Western understanding of conversion. They cite the work of Robin Horton (1971) on conversion in Africa as an example of interdisciplinary work needed to bridge individual and socio-cultural explanation of religious motivation. The authors emphasize that a psychology of conversion in China will need to examine the various forces that influence a Chinese psychology (Bond 2010).

While some of the authors are concerned about the Western cultural context of psychological theories, there are writers in this volume who suggest the relevance of some Western approaches in China. Louis Hoffman proposes in his essay "An ExistentialPhenomenological Approach to the Psychology of Religion" the usefulness of an existential-phenomenological approach with its emphasis on the experiential for the psychology of religion research in China. At this point more research in Chinese psychology of religion is conducted in an empiricist research model and as Chen points out in his chapter there is a need for alternate models. Hoffman's proposal is potentially a complementary 
perspective. He emphasizes the importance of meaning making personally and culturally and unique subjective experience, rather than objective, universal descriptions. Building on the work of Frank1, Rollo May, Irving Yalom and Kirk Schneider, he suggests some themes: the meaning of existence, importance of subjective experience, holistic ways of knowing, honesty and directness in facing life; concern for the givens of human existence including death, finitude, freedom, agency, relationality and human emotions. As a movement, existentialists in the West have both affirmed and critiqued religion. When existentialism is applied to religion, the experiential nature of religion is made salient. Psychologists of religion would then do well to engage in qualitative interviews (and quantitative methods) with religious adherents so as to ascertain their spiritual beliefs about the meaning of life, their subjective spiritual experiences system, their willingness to face their spirituality honestly and one's understanding of religion in terms of narrative and myth.

Rambo, Bauman, and Fenjiang in their paper "Toward a Psychology of Converting in the People's Republic of China," address the issues to be considered in constructing a psychology of converting in China. Central to the argument of their paper is that given the complexity and diversity of converting (for the authors a more dynamic term than conversion) processes in China, psychologists of religion must work collaboratively. With more than a billion people, 56 nationalities, phoenix like economic growth, and the largest human migration in human history from the countryside to the expanding cities, no one person can grasp the nature of how and why people are turning to a multitude of religious and spiritual beliefs and practices. They acknowledge that the usefulness of the term "religion" has been contested in China given that has the ring of Christian overtones. The centerpiece of this chapter is Fengjiang's ethnographic case study of five university students converting to Christianity. At a time in their life when they are in transition, when they are exposed to many new values and ideas, Christianity seems to fill a vacuum or helping them to connect the dots. The authors engage in an analysis of the socio-psychological factors that contribute to converting such as social interactions with others, the communal dimension of Christianity, the exposure to Western culture, failure in dating relationships, and community support. The intellectual quest approach seemed underrepresented. The specific issues that should be given attention in a psychology of converting in China include methods of research, gender, motivation, network theory, cultural psychology, and interdisciplinary collaboration.

Louis Hoffman is concerned in another essay entitled "Religious Experience in a Crosscultural and Interfaith Context: Limitations and Possibilities" to situate religious experience in a cross-cultural and interfaith context. He begins by making a distinction between one's image and concept of God; the latter is more cognitive in nature while the former more emotive and unconscious. Hoffman makes the point that what is at stake is not the actual existence of God but rather the persons subjective experience of transcendence. And, how one subjectively perceives God is predicted to influence mental health in terms of depression and anxiety. In the West attachment to God is viewed as an individual experience; religion is private not public. God is perceived as rewarding and punishing individuals more than groups. In a preliminary study in the US comparing Caucasian and non-white populations (more collectivistic), in the former more identified themselves as spiritual and in the latter more indicated they were spiritual and religious. Indicating one was spiritual and religious was more closely associated with a positive experience of God. Hoffman comments: "With many minority groups in the United States, organized religion is highly social and provides an important source of support. Conversely, in the dominant culture, organized religion is often perceived of as being restrictive, oppressive, and corrupt." He predicts that in China's more collective culture, the way one experiences God would be different than in the United 
States but he is concerned about the lack of instruments that are sensitive to communal spirituality.

Methodology: Interdisciplinary, diverse and practical

Lewis Rambo and Matthew Haar Farris, in their article "Psychology of Religion: Toward a Multidisciplinary Paradigm," applaud the recent development of Chinese and American psychologists who together are studying spirituality and religion. The authors argue that given the manifold religions in each of their countries, a culturally sensitive psychology of religion will need to embrace a multidisciplinary approach to explore spirituality as is exemplified by the soon to be published The Oxford Handbook of Religious Conversion. This will mean that psychologists of religion engage the sociology of religion, anthropology of religion, and religious studies. Experts in each field will need the courage to cross disciplinary boundaries without feeling they are leaving behind their distinctive contribution. We will need scholars in religious studies who can help us, for example, to understand what constitutes a "true" conversion given the constellations of beliefs and convictions of a religious group. Phenomenologists of religion are sensitive to the contours of religious experience while historians of religion note that a becoming a Christian in $19^{\text {th }}$ century China is different in contemporary Chinese Christianity. In particular the authors highlight the importance of indigenous and cultural psychology. It is increasingly apparent that Western psychology reflects western culture. Cultural psychologists advocate understanding psychology of religion within the worldviews, assumptions, rituals, philosophies of local cultures.

Brent Slife and Brent Melling address the issue methodology in their chapter, "Method Decisions: The Advantages and Disadvantages of Quantitative and Quantitative Modes of Inquiry." Slife and Melling's methodological assessment of quantitative and qualitative methods is relevant since much of the research in psychology of religion in the US and also in China is quantitative in nature. Some dimensions of religiousness are quantifiable (attendance at meetings, donations) but some are not (symbolic meanings, ritual significance). Some methods seem to provide richer results with certain phenomena. However Western methods are often construed as non-debatable procedures as opposed to outcomes of different interpretations and different philosophies of science. (1) Empirical methods work better with observable behaviors (hugging) while qualitative approaches are better when studying nonobservable meanings (love). (2) If we are seeking universals regardless of context, a quantitative methodology is preferable because it may be generalized to new situations. Qualitative methods are more sensitive to contextual particulars as in William James study of varieties of unique religious experiences. (3) Quantitative approaches are less sensitive to symbolic meanings or texture of statements about experiencing closeness to God, for example. It requires translating one's religious experience into the language of numbers but qualitative approaches begin with the language the participant uses to describe his or her religious experiences. (4) If quantitative models discover natural laws that govern human behavior, then ultimately humans are forced to act as they do because of these laws. However, many religious persons believe they are making decisions of their own free will according to personal reasons or convictions. (5) Quantitative methods are presumed to provide objectivity and avoid subjective bias. Qualitative researchers assume that the subjective values and biases are inevitable and necessary for increased understanding. Hence these values and biases are monitored and made public. In the end, the Slife and Melling argue for that methodology which best matches the issue being explored. They are intrigued with Chen Yongsheng's project of developing intentionally a more dialectical materialist 
approach to the psychology of religion aware that most Western researchers would assume it is inappropriate.

\section{Conclusion}

The essays in this double issue of the journal Pastoral Psychology, are the result of years of collaboration, many long conversations at conferences over tea, and a long trail of e-mails seeking mutual understanding. We have been changed by the process of cultural engagement over issues and topics we are passionate about. May the conversation continue.

\section{References}

Belzen, J. A. (2009). Towards cultural psychology of religion: Principles, approaches, applications. Dordrecht: Springer.

Bond, M. H. (Ed.). (2010). Oxford handbook of Chinese psychology. Oxford: Oxford University Press.

Chen, Y., Liang, H., \& Lu, L. (2006). PERSPECTIVE: psychology of religion in China. The International Journal for the Psychology of Religion, 16, 153-161.

Chen, B. (2003). Erikson's thought of religious psychology and its contribution. Studies in World Religions, 24(4), 93-102. doi: CNKI:ISSN:1000-4289.0.2003-04-011.

Confucius. (1997). The Analects of Confucius. New York, W.W. Norton.

Fingarette, H. (1972). Confucius: The secular as sacred. New York: Harper \& Row.

Han, B., \& Dueck, A. (in press). Chinese Psychology of Religion. Shanghai: Chinese Academy of Social Sciences.

Han, B., \& Zhang, K. (2007). Psychology in China. The Psychologist, 20(12), 734-736.

Hood, R. W., Hill, P. C., et al. (2009). The psychology of religion: An empirical approach. New York; London: The Guilford Press.

Horton, R. (1971). African conversion. Africa, 41(2), 85-108.

Jeeves, M. A., \& Brown, W. S. (2009). Neuroscience, psychology, and religion illusions, delusions, and realities about human nature. West Conshohocken, PA: Templeton Foundation Press.

Jing, Q., \& Fu, X. (2001). Modern Chinese psychology: Its indigenous roots and international influences. International Journal Of Psychology, 36(6), 408-418. doi:10.1080/0020759014300023 4.

Landau, J. \& Weaver A. M. (2006). The LINC model of family and community resilience: new approaches to disaster response. Journal of Family and Consumer Sciences, 98, 11-14.

Liang, L. P. (2003). The investigation and analysis regarding religious identity. Studies in World Religions, 25 (3), 34-44. doi: CNKI: ISSN:1000-4289.0.2003-03-006.

Mou, Z., \& Zhang, J. (2000). General history of Chinese religions. Beijing: Social Literature Press.

Nelson, J. M. (2009). Psychology, religion, and spirituality. New York: Springer.

Paloutzian, R. F., \& Park, C. L. (2005). Handbook of the psychology of religion and spirituality. New York: Guilford Press.

Pargament, K. I. (1997). The psychology of religion and coping: Theory, research, practice. New York: Guilford Press.

Shan, J. (2010). Growing interest in religious tourism. China Daily, 2010-11-19. Accessed 2011-2-3.

Walsh, F. (2007). Traumatic loss and major disasters: strengthening family and community resilience. Family Process, 46, 207-227.

Wu, J. (2007). Religious believers thrice the estimate. China Daily, 2007-01-07. Accessed 12 July 2010.

Wulff, D. M. (1991). Psychology of religion: Classic and contemporary views. New York: Wiley.

Yin, Y., \& Yang, Y. (2010). The cultural basis and feasibility of the post-quake "bare-foot psychotherapist.". Schweizer Archiv Für Neurologie and Psychiatrie, 161, 316-318. 